\title{
Reasons for Poor Medication Adherence in Patients with Depression
}

\author{
D. Sri Chaitanya ${ }^{1 *}$, S. Mounika ${ }^{1}$, M. Chiranjeevi ${ }^{1}$, \\ Sk. Shafiya Begum ${ }^{1}$, N. Uma Jyothi ${ }^{2}$
}

\section{ABSTRACT}

Background: Depression is one among the disorders that have always been targeted by researchers in India. In South India the prevalence is $15.1 \%$. Large number of studies has been published from India revealing various aspects of this commonly prevalent disorder, but there is limited evidence for the non-adherence to anti depressants in India. Aim: To assess the reasons contributing for non adherence in patients with depression. Method: This is a prospective, observational study, conducted in a tertiary care teaching hospital, Guntur. Medication adherence was assessed using the eight-item Morisky Medication Adherence Scale (MMAS-8) and a self administered questionnaire during the period of 1st February 2015 to 31st July 2015(i.e. 6months). Results: A total of 60 patients met the inclusion criteria; $68.3 \%$ are females and 31.6\% are males. Among those, 3 (5\%) are highly adherent, 17 (28.33\%) are moderately adherent and $40(66.67 \%)$ are poorly adherent. Conclusion: The overall Non adherence rate is found to be high in the study. The results presented suggest that pharmacist instructions may improve adherence in depression. Clinical pharmacist in this regard has a major role to play in uplifting and improving the quality of life of the patient.

Keywords: Depression, Adherence, Non Adherence, Morisky Medication Adherence Scale, Self administered questionnaire.

Anti depressants are commonly considered as a critical tool in the treatment of depression but they are useless if medication adherence is not improved. Although clinical guidelines recommend antidepressants be continued for at least 6 months after symptom remission, approximately one third of patients discontinue antidepressants within the first month of treatment, and $44 \%$ discontinue them by the third month of treatment. Poor adherence to antidepressant medications in depressive patients may lead to several complications like disease recurrence, relapse, increase in the cost of treatment, and impairment in daily functioning,

\footnotetext{
${ }^{1}$ Chalapathi Institute of Pharmaceutical Scienceslam, Guntur. Guntur Andhra Prdesh \& India

${ }^{2}$ Assistant Professor, Dept of Psychiatry, Govt. General Hospital, Guntur, India

*Responding Author

(C) 2016 I D Chaitanya, S Mounika, M Chiranjeevi, S Begum, U Jyothi; licensee IJIP. This is an Open Access Research distributed under the terms of the Creative Commons Attribution License (http://creativecommons.org/licenses/by/2.0), which permits unrestricted use, distribution, and reproduction in any Medium, provided the original work is properly cited.
} 
increased suicide rates. Patients with depression themselves have a risk of suicide that is 20 times above normal. Non adherence leads to increase in suicidal a rate which leads to increase in mortality.

\section{INTRODUCTION}

Depressive disorder is one of the most prevalent forms of mental illness, and is of major public health importance. ${ }^{1}$ Depression is a term used to describe a health problem in which mood pattern will be affected. However when our mood becomes excessively low, remains low for more than a two-week period and interferes with our ability to live our lives then this is called Clinical Depression. ${ }^{2}$ Most common types of depression are Major depression, Dysthymic disorder, Psychotic depression, Postpartum depression, Seasonal affective disorder, Bipolar disorder.

\section{Epidemiological facts on depression globally and in India}

- It accounts for $5 \%$ of total burden of disease from all causes.

$-14,582$ thousand DALY's due to depression which is $3.6 \%$ of DALY's due to all causes. ${ }^{3}$

- Lifetime prevalence $12.1 \%$.

-Suicide mortality rate of 16 per $100,000 .^{4}$

-Prevalence of $26.3 \%$ in 1999 in South Asia. ${ }^{5}$

-Suicide mortality rate of 10.5 per 100,000 in $2006 .^{6}$

Medications recommended for initial treatment of depression include selective serotonin reuptake inhibitors (SSRIs - fluoxetine, paroxetine, sertraline, citalopram, and escitalopram), serotonergic noradrenergic reuptake inhibitors (SNRIs - venlafaxine and duloxetine), bupropion, and mirtazapine. All these antidepressants are considered similar in regard to efficacy (Level A data. - evidence derived from randomized, controlled clinical trials), with treatment selection based upon individual patient, characteristics (comorbidities, concomitant medication, treatment history) and patient preference. ${ }^{7}$ In addition to ADM, other treatments are effective in alleviating depression. These include cognitive therapy (CT) and other forms of psychotherapy, such as interpersonal therapy, electroconvulsive therapy and electrical stimulation of the vagus nerve. ${ }^{8}$

Adherence is the extent to which a person's behavior of taking medication, following a diet, or making healthy lifestyle changes corresponds with agreed-upon recommendations from a healthcare provider. This definition implies that the patient has a choice and that both patients and providers mutually establish treatment goals and the medical regimen. ${ }^{9}$ Medication adherence is a growing concern to clinicians, healthcare systems, and other stakeholders (eg. payers) because of mounting evidence that nonadherence is prevalent and associated with adverse outcomes and higher costs of care. ${ }^{10}$

The 8-item Morisky Medication adherence scale was used in the study and the scores were categorized as 0-6 (low adherence), 6-8 (moderate adherence) and 8 (high adherence). For the 
purpose of analysis and ease of comparison the scale was again categorized in to non adherent patients (combining low adherence and moderate adherence) and adherent patients (high adherence).

\section{METHODOLOGY}

A Prospective observational study was conducted from February to July 2015 i.e 6 months in an Outpatient Department of Psychiatry in a tertiary care teaching hospital, Guntur, Andhra Pradesh. Materials used were patient consent form, patient data collection form, MMAS-8 Scale, self administered questionnaire.

\section{INCLUSION CRITERIA:}

- Patients in the age group of 20-60 years.

- Patients who are willing to give consent for the study.

- Patients who are already diagnosed with depression and without any other comorbidities

\section{EXCLUSION CRITERIA:}

- Patients who require urgent attention for medical problems.

- Patients without reliable informants.

- $\quad$ Patients with depression and are admitted.

\section{STUDY METHOD:}

- Study is conducted in a 1300 bedded tertiary care hospital, Guntur,.

- Patients who satisfy study criteria will be included in the study.

- Consent of the patient will be taken if the patient is literate or else the nature of the study will be explained to the reliable informants and signature will be taken from the witness.

- The patients are then administered MMAS-8 scale and self administered questionnaire.

\section{RESULTS:}

Total number of patients screened for the in the outpatient block of Department of Psychiatry were 240. Out of 240 patients only 60 patients were included in the study. The study was conducted during the period of $1^{\text {st }}$ February to $31^{\text {st }}$ July

\section{Table 1: Age and Gender Wise Distribution}

\begin{tabular}{|l|l|l|l|l|}
\hline Age group & Males & Females & Total & Percentage (\%) \\
\hline $\mathbf{2 1 - 3 0}$ & 09 & 10 & 19 & 31.6 \\
\hline $\mathbf{3 1}-\mathbf{4 0}$ & 03 & 12 & 15 & 25 \\
\hline $\mathbf{4 1 - 5 0}$ & 06 & 15 & 21 & 35 \\
\hline $\mathbf{5 1 - 6 0}$ & 01 & 04 & 05 & 8.3 \\
\hline
\end{tabular}

Majority of patient population fall between the age group of 41 - 50 years i.e. 35\%. The study was dominated by females $68.3 \%(n=41)$ than males $31.6 \%(n=19)$. 
Reasons for Poor Medication Adherence in Patients with Depression

Table 2: Socio-Demographic Characteristics of the Respondents $(N=60)$ :

\begin{tabular}{|c|c|c|c|c|c|}
\hline & High & Medium & Low & Total & Percentage (\%) \\
\hline \multicolumn{6}{|l|}{ Females } \\
\hline 21-30 & $02(20 \%)$ & $05(50 \%)$ & $03(30 \%)$ & 10 & 16.67 \\
\hline $31-40$ & 00 & $02(16.67 \%)$ & $10(83.33 \%)$ & 12 & 20 \\
\hline $41-50$ & 00 & $01(6.67 \%)$ & 14(93.33\%) & 15 & 25 \\
\hline $51-60$ & 00 & 00 & $04(100 \%)$ & 04 & 6.67 \\
\hline \multicolumn{6}{|l|}{ Males } \\
\hline 21-30 & 01(11.11\%) & $06(66.66 \%)$ & 02(33.33\%) & 09 & 15 \\
\hline $31-40$ & 00 & $01(33.33 \%)$ & $02(66.67 \%)$ & 03 & 5 \\
\hline $41-50$ & 00 & $02(33.33 \%)$ & $04(66.67 \%)$ & 06 & 10 \\
\hline 51-60 & 00 & 00 & $01(100 \%)$ & 01 & 1.66 \\
\hline \multicolumn{6}{|c|}{ Educational status } \\
\hline Iliteraterates & 00 & $04(19.05 \%)$ & $17(80.95 \%)$ & 21 & 35 \\
\hline Primary & 00 & 06(33.33\%) & $12(66.67 \%)$ & 18 & 30 \\
\hline Secondary & $01(7.15 \%)$ & $05(35.71 \%)$ & 08(57.14\%) & 14 & 23.33 \\
\hline Higher & $02(28.57 \%)$ & $02(28.57 \%)$ & $03(42.86 \%)$ & 07 & 11.67 \\
\hline \multicolumn{6}{|c|}{ Bread winner } \\
\hline Yes & 00 & $06(24 \%)$ & $19(86 \%)$ & 25 & 41.66 \\
\hline No & 03(8.57\%) & $11(31.43 \%)$ & $21(60 \%)$ & 35 & 58.33 \\
\hline \multicolumn{6}{|c|}{ Occupational status } \\
\hline Cooley & 00 & $05(27.8 \%)$ & $13(72.2 \%)$ & 18 & 30 \\
\hline Agriculture & 00 & 00 & $04(100 \%)$ & 04 & 6.66 \\
\hline Employee & $02(25 \%)$ & $04(50 \%)$ & $02(25 \%)$ & 08 & 13.33 \\
\hline Business & 00 & $02(66.67 \%)$ & 01(33.33\%) & 03 & 05 \\
\hline House wife & $01(3.84 \%)$ & $06(23.07 \%)$ & $19(73.07 \%)$ & 26 & 43.33 \\
\hline Student & 00 & 00 & $01(100 \%)$ & 01 & 01.66 \\
\hline \multicolumn{6}{|c|}{ Marital status } \\
\hline Married & 03(6.5\%) & $17(42.5 \%)$ & $20(50 \%)$ & 40 & 66.66 \\
\hline Un married & 00 & 00 & 09(100\%) & 09 & 15 \\
\hline Widowed & 00 & 00 & $05(100 \%)$ & 05 & 08.33 \\
\hline Divorced & 00 & 00 & $06(100 \%)$ & 06 & 10 \\
\hline \multicolumn{6}{|l|}{ Habits } \\
\hline Alcoholic & $01(6.67 \%)$ & $04(26.67 \%)$ & $10(66.66 \%)$ & 15 & 78.94 \\
\hline Smoker & $01(5.88 \%)$ & $06(35.29 \%)$ & $10(58.83 \%)$ & 17 & 89.47 \\
\hline \multicolumn{6}{|c|}{ Year of diagnosis } \\
\hline 2008 & $02(16.67 \%)$ & $05(41.66 \%)$ & $05(41.67 \%)$ & 12 & 20 \\
\hline 2009 & 01(16.67\%) & $03(50 \%)$ & 02(33.33\%) & 06 & 10 \\
\hline
\end{tabular}


Reasons for Poor Medication Adherence in Patients with Depression

\begin{tabular}{|c|c|c|c|c|c|}
\hline 2012 & 00 & $03(30 \%)$ & $07(70 \%)$ & 10 & 16.67 \\
\hline 2013 & 00 & $02(25 \%)$ & $06(75 \%)$ & 08 & 13.33 \\
\hline 2014 & 00 & $03(15 \%)$ & $17(85 \%)$ & 24 & 40 \\
\hline 2015 & 00 & 00 & $04(100 \%)$ & 04 & 6.67 \\
\hline \multicolumn{6}{|c|}{ Economical status } \\
\hline I & $02(100 \%)$ & 00 & 00 & 02 & 3.33 \\
\hline II & $01(25 \%)$ & 02(50\%) & $01(25 \%)$ & 04 & 6.67 \\
\hline III & 00 & $03(60 \%)$ & $02(40 \%)$ & 05 & 8.33 \\
\hline IV & 00 & $06(40 \%)$ & $09(60 \%)$ & 15 & 25 \\
\hline V & 00 & $06(25 \%)$ & $18(75 \%)$ & 24 & 40 \\
\hline \multicolumn{6}{|c|}{ Previous admission } \\
\hline Nil & 00 & $04(16.67 \%)$ & 20(83.33\%) & 24 & 40 \\
\hline 1 & 00 & $03(20 \%)$ & $12(80 \%)$ & 15 & 25 \\
\hline 2 & $01(10 \%)$ & $05(50 \%)$ & $04(40 \%)$ & 10 & 16.67 \\
\hline 3 & $02(50 \%)$ & $01(25 \%)$ & $01(25 \%)$ & 04 & 6.67 \\
\hline 4 & 00 & $02(40 \%)$ & $03(60 \%)$ & 05 & 8.33 \\
\hline 5 & 00 & 00 & $02(100 \%)$ & 02 & 3.33 \\
\hline
\end{tabular}

There are more number of illiterate patients $(n=21,35 \%)$ and less number highly educated patients $(n=7,11.67 \% \%)$ in the study. The subjects were predominantly married $(n=40$, $66.66 \%)$ compared to unmarried $(n=9,15 \%)$, widowed $(n=5,8.33 \%)$, divorced $(n=6,10 \%)$ patients. More number of patients in our study are not bread winners $(n=35,58.33 \%)$ in their family. The most frequently reported occupation was housewives $(n=26,43.33 \%)$ because there are more number of female patients. From the study it was found that among 19 male patients with depression, $89 \%(\mathrm{n}=17)$ and $79 \%(\mathrm{n}=15)$ presented with smoking history and alcohol consumption respectively. More number of patients are diagnosed by depression in $2014(\mathrm{n}=24$, $40 \%)$. There are more number of patients who are not admitted as inpatients $(n=24,40 \%)$ for the treatment before. There are more number of economically lower class $(n=24,40 \%)$ patients in our study.

Table 3: Categorisation Based On ADRS Observed:

\begin{tabular}{|l|l|l|}
\hline ADR & No. Of Cases & \% of Cases \\
\hline Weight gain & 07 & 28 \\
\hline Fatigue & 01 & 04 \\
\hline Tiredness & 05 & 20 \\
\hline Headache & 06 & 24 \\
\hline Nausea & 01 & 04 \\
\hline Body cramps & 01 & 04 \\
\hline Dizziness & 03 & 12 \\
\hline Loss of appetite & 01 & 04 \\
\hline Total & 25 & 100 \\
\hline
\end{tabular}


Among 60 patients, 25 Adverse Drug Reactions were observed in 23(38.33\%) patients. weight gain is reported by more number of patients $(n=7,28 \%)$

Figure 1: Level of Medication Adherence

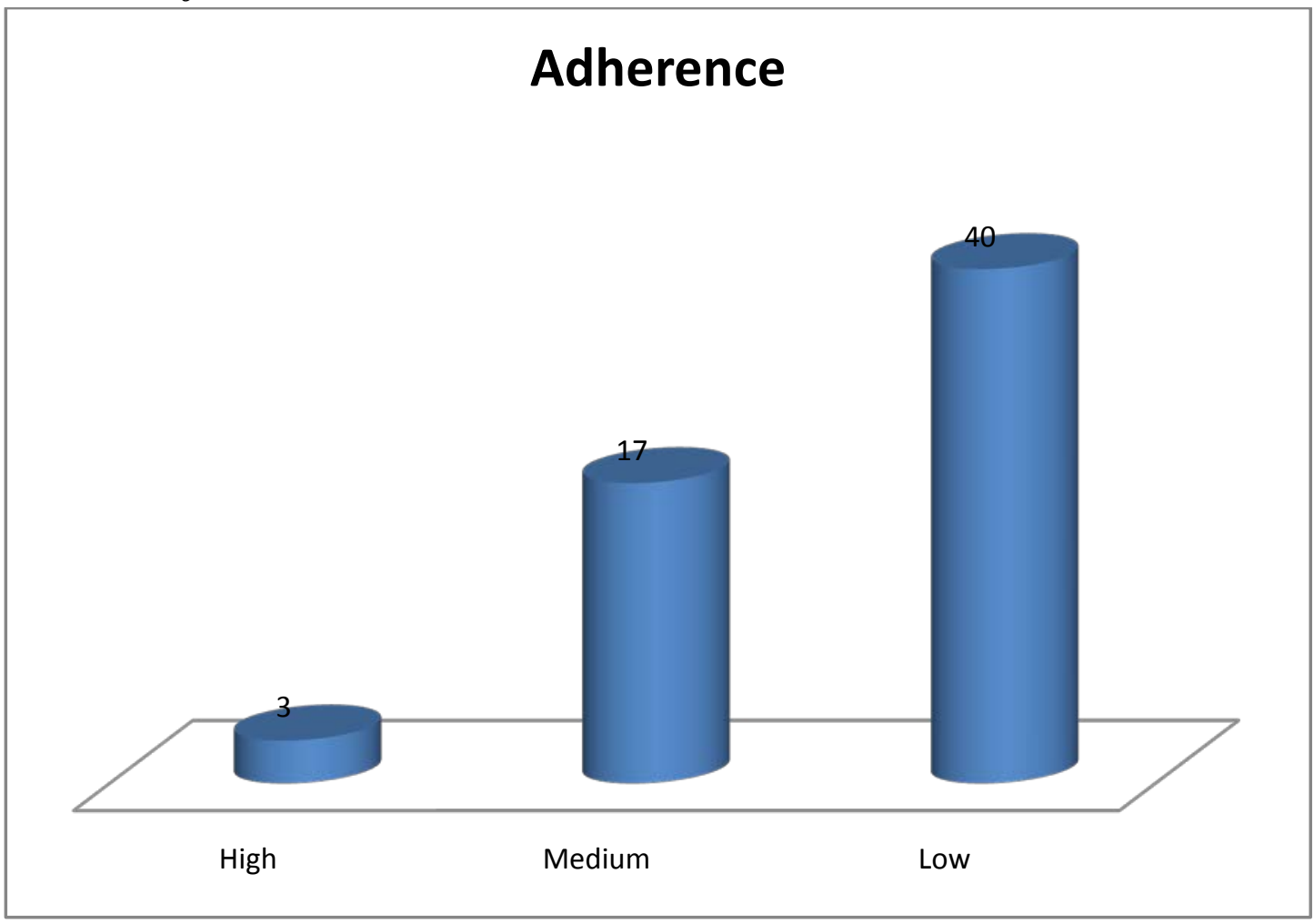

Among the 60 depressive patients 3 (5\%) are highly adherent, 17 (28.33\%) are moderately adherent and 40 (66.67\%) are poorly adherent.

Table 4: Findings of Self Administered Questionnaire

\begin{tabular}{|c|c|c|c|c|}
\hline QUESTIONS & & HIGH & MEDIUM & LOW \\
\hline Are you taking medications regularly & $\begin{array}{l}\text { Yes } \\
\text { No }\end{array}$ & $\begin{array}{l}03 \\
00\end{array}$ & $\begin{array}{l}12 \\
05\end{array}$ & $\begin{array}{l}18 \\
22\end{array}$ \\
\hline $\begin{array}{l}\text { Any of your family members supervising your } \\
\text { medications }\end{array}$ & $\begin{array}{l}\text { Yes } \\
\text { No }\end{array}$ & $\begin{array}{l}03 \\
00\end{array}$ & $\begin{array}{l}09 \\
08\end{array}$ & $\begin{array}{l}15 \\
25\end{array}$ \\
\hline $\begin{array}{l}\text { Do you find any benefits after using these } \\
\text { medications }\end{array}$ & $\begin{array}{l}\text { Yes } \\
\text { No }\end{array}$ & $\begin{array}{l}03 \\
00\end{array}$ & $\begin{array}{l}10 \\
07\end{array}$ & $\begin{array}{l}19 \\
21\end{array}$ \\
\hline Do you know how long to use these medications & $\begin{array}{l}\text { Yes } \\
\text { No }\end{array}$ & $\begin{array}{l}02 \\
01\end{array}$ & $\begin{array}{l}07 \\
10\end{array}$ & $\begin{array}{l}10 \\
30\end{array}$ \\
\hline $\begin{array}{l}\text { Do you have any worries regarding your } \\
\text { medications }\end{array}$ & $\begin{array}{l}\text { Yes } \\
\text { No }\end{array}$ & $\begin{array}{l}00 \\
03\end{array}$ & $\begin{array}{l}09 \\
08\end{array}$ & $\begin{array}{l}22 \\
18\end{array}$ \\
\hline $\begin{array}{l}\text { Did you discussed your doubts and worries with } \\
\text { your clinician }\end{array}$ & $\begin{array}{l}\text { Yes } \\
\text { No }\end{array}$ & $\begin{array}{l}03 \\
00\end{array}$ & $\begin{array}{l}13 \\
04\end{array}$ & $\begin{array}{l}13 \\
27\end{array}$ \\
\hline
\end{tabular}


Reasons for Poor Medication Adherence in Patients with Depression

\begin{tabular}{|l|l|l|l|l|}
\hline What is your family's attitude towards your & Yes & 03 & 12 & 19 \\
condition & No & 00 & 05 & 21 \\
\hline What is your family's attitude towards your & Yes & 03 & 12 & 19 \\
medicines & No & 00 & 05 & 21 \\
\hline Do you believe these medications will help to & Yes & 03 & 10 & 22 \\
reach your normal life & No & 00 & 07 & 18 \\
\hline Do you believe these medications will help to & Yes & 03 & 15 & 25 \\
prevent the disease from retaining & No & 00 & 02 & 12 \\
\hline By long medication, did you identify any side & Yes & 01 & 06 & 28 \\
effects & No & 02 & 11 & 12 \\
\hline Are you worried about side effects & Yes & 00 & 04 & 26 \\
& No & 03 & 13 & 14 \\
\hline Are you attending your regular follow-ups & Yes & 03 & 14 & 18 \\
& No & 00 & 03 & 22 \\
\hline Any of your family members or friends opposed & Yes & 00 & 02 & 05 \\
you to take medicines & No & 03 & 15 & 35 \\
\hline Do you have any financial problem in attending & Yes & 01 & 10 & 30 \\
follow-ups & No & 02 & 07 & 10 \\
\hline Do you believe that you need medication correctly & Yes & 03 & 16 & 38 \\
& No & 00 & 01 & 02 \\
\hline
\end{tabular}

Among 60 patients, 33(55\%) are taking medications regularly. 27(45\%) patient's family members are supervising their medications. 19(37.67\%) patients have agreed that they could find benefits with the medications. 19(37.67\%) patients said that they are aware of how long to use the medication. 31(51.66\%) patients said that they have worries regarding the medication. Few patients 29(48.33\%) said that they discussed with clinician about medication doubts and worries. Few patients 34(56.66\%) agreed that their family's attitude is supportive towards their condition. $37(61.66 \%)$ patients believed that medication will help them to reach their normal life. 40(66.66\%) patients believe that medications will help to prevent the condition from retaining. 35(58.33\%) patients answered that by long term medication use, they have identified side effects. 30(50\%) patients complained of they are worrying about side effects. 35(58.33\%) patients said that they are attending regular follow ups. 14.7(11.66\%) whom have agreed that their family members or friends are opposing them to take medicines. 41(68.33\%) patients have said that they have financial problem in attending follow-ups. 57(95\%) patients believed that they need medication correctly. 
Figure 2: Findings of Self Administered Questionnaire

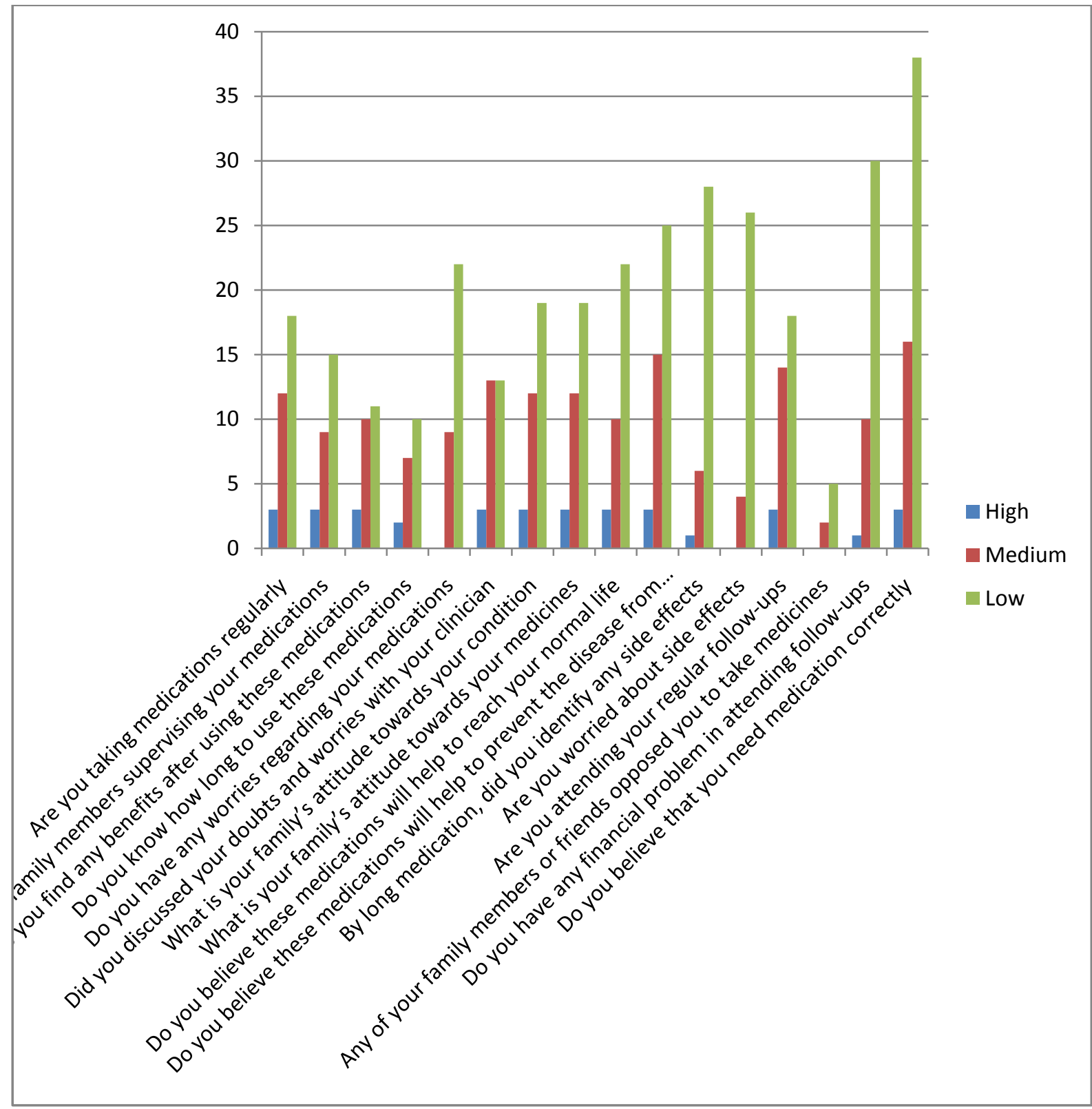

\section{DISCUSSION:}

According to MMAS-8 scale among the 60 depressive patients 3 (5\%) are highly adherent, 17 (28.33\%) are moderately adherent and 40 (66.67\%) are poorly adherent (as shown in Figure 1). According to Sohini Banerjee et.al.(2012) ${ }^{11} 46$ (19.2\%) were highly adherent, 33 (13.8\%) were moderately adherent and 160 (66.9\%) were poorly adherent.

Females are more non adherent than males in our study (as shown in Table 2) similar to Ignacio Martinez Parraga et.al.(2013) ${ }^{12}$ study. Highest adherence was observed in the age group of 2130 years and poor adherence was observed in the age group of 51-60 years (as shown in Table 
2), but Sri Harsha et. al. (2015) ${ }^{13}$ study shows highest non adherence was in the age group of 31-40years and low adherence was observed in the age group of 61-70 years.

Illiterates are showing highest non adherence compared to highly educated people in our study which is also stated by Ignacio Martinez Parraga et.al.(2013). ${ }^{12}$ A total of 60 patients 21(35\%) are illiterates in which $4(19.05 \%)$ are moderately adherent where as $17(80.95 \%)$ are poorly adherent; 18 (30\%) are educated up to primary level in which $6(33.33 \%)$ are moderately adherent and the remaining $12(66.67 \%)$ are poorly adherent; $14(23.33 \%)$ are educated up to secondary level in which $1(7.15 \%)$ was highly educated, $5(35.71 \%)$ are moderately adherent and 8 (57.14\%) are poorly adherent; among 7 (11.67\%) of highly educated patients 2 (28.57\%) are highly adherent, 2 (28.57\%) are moderately adherent and 3 (42.86\%) are poorly adherent (as shown in Table 2).

Alcoholics and smokers having low adherence. There are 15 (25\%) patients who are alcoholics among them 1 (6.67\%) was highly adherent, 4 (26.67\%) are moderately adherent and 10 (66.66\%) are poorly adherent (as shown in Table 2). There are 17 (28.33\%) patients who are smokers among them 1 (5.88\%) was highly adherent, 6 (35.29\%) are moderately adherent and 10 (58.83\%) are poorly adherent (as shown in Table 2).

Bread winners having high adherence compared to those of patients who are not bread winner in their families. There are 25 (41.67\%) patients who are bread winners in their family in which 6 (24\%) are moderately adherent, 19 (86\%) are poorly adherent. In remaining 35 (58.33\%) patients 3 (8.57\%) are having high adherence, 11 (31.43\%) are having moderate adherence and 21 (60\%) having low adherence (as shown in Table 2).

According to occupation of patients who are employees and businessmen having high adherence compared to housewives and daily labors which is similar to the Sohini Banerjee et.al.(2012). ${ }^{11}$ There are 18 (30\%) patients who works as Cooley in those patients 5 (27.8\%) are moderately adherent and $13(72.2 \%)$ are poorly adherent. 4 (6.67\%) of patients are on agriculture where all are poorly adherent. 8(13.33\%) are employees among them 2 (25\%) are highly adherent, 4(50\%) are moderately adherent and 2(25\%) are poorly adherent. 3(5\%) patients are in business in which 2(66.67\%) are moderately adherent, 1(33.3\%) has low adherence. 26(43.33\%) are housewives among them 1 (3.84\%) has high adherence, 6(23.07\%) have moderate adherence, 19(73.07\%) has low adherence. $1(1.67 \%)$ is student who is a student (as shown in Table 2).

Considering marital status more number of patients are married 40(66.67\%) who are more adherent $(50 \%)$ than the patients who are unmarried $(n=9,15 \%)$, widowed $(n=5,8.33 \%)$, divorced ( $\mathrm{n}=6,10 \%$ ) (as shown in Table 2), which is similar to Ignacio Martinez Parraga et.al.(2013). ${ }^{12}$ According to economic status of the patients who are in upper class (class I) having high adherence, and patients in lower class (class II) are having low adherence (as shown in Table 2) which is similar to Ignacio Martinez Parraga et.al.(2013). ${ }^{12}$ 
Considering the previous admissions of patients who are having no admissions and having more number of admissions are poorly adherent to the medications where as patients having 2 or 3 admissions are highly adherent (as shown in Table 2), but in the study of Sri Harsha et.al. (2015) $^{13}$ stated that whether the number of admissions increased then the non-adherence to the medications was decreased. There are 25 ADR's reported by 23 patients in which 8(34.78\%) are adherent and 15(65.22\%) are non adherent with the treatment (as shown in Table 3), which is similar to Ignacio Martinez Parraga et.al.(2013) ${ }^{12}$ in which $36.4 \%$ were adherent and $45.6 \%$ were non adherent.

According to self administered questionnaire, among 33(55\%) patients who said yes for whether they are taking medications regularly, 15(45.45\%) are adherent and $18(54.54 \%)$ are non adherent (as shown in Table 4). Among 27(45\%) patients who said yes for that their family members are supervising their medications 14(51.85\%) are adherent and 13(48.15) are non adherent (as shown in Table 4). This study found supervised treatment to be a good predictive factor for treatment adherence. There is in agreement with Fenton SW et.al. (1997) ${ }^{14}$ which reported that supportive behavior provided by caregivers may reinforce medication usage and that higher medication usage may elicit supportive behavior from caregivers and this create a therapeutic chain of events. In a total of $19(37.67 \%)$ patients who have agreed that they could find benefits with the medications, 13(40.62) are adherent where as 19(59.37\%) are non adherent (as shown in Table 4).

Among 19(37.67\%) who said that they know how long to use the medication 9(47.36\%) are adherent and 10(52.64\%) are non adherent (as shown in Table 4). There are 31(51.66\%) patients who said that they have worries regarding the medication, 9(29\%) are adherent where as 22(71\%) are non adherent (as shown in Table 4). In a total of 29(48.33\%) who has said that they discussed with clinician about medication doubts and worries, 16(55.17\%) are adherent and 13(44.83\%) are non adherent (as shown in Table 4). This is in accordance with recent evidence which suggests that physician-patient congruence on their preferences for patient involvement in care is more important than congruence on demographic variables such as ethnicity, age, or gender Jahng et. al. (2005).$^{15}$ Cohesive partnerships and effective interpersonal communication make it possible for patients and physicians to work together to help patients follow mutually agreed upon recommendations. Effective interactions between patients and health care practitioners have been shown to be important in patient's acceptance of antidepressants and continuation of treatment. (Bultman DC et.al. 2000). ${ }^{16}$

Among 34(56.66\%) who has agreed that their family's attitude is supportive towards their condition,19(64.7\%) are adherent where as 12(35.3\%) are non adherent (as shown in Table 4). This is in accordance with the study Solberg LI et.al. (2003) ${ }^{17}$ that states social support from family or household members in patients with chronic disease has long been thought to be a factor that facilitates treatment adherence, but this has not often been tested specifically particularly in the antidepressant medication literature. Among 34(56.66\%) who has agreed that 
their family's attitude is supportive towards their medication, 19(64.7\%) are adherent where as 12(35.3\%) are non adherent (as shown in Table 7). This is in relevance with other studies such as Sirey JA et.al. (2001), ${ }^{18}$ Kadam Ut et.al. (2001). ${ }^{19}$ The environment and the social support available to patients also affect their willingness to adhere, especially when dealing with such conditions as depression carries a potential stigma.

Among 37(61.66\%) who believed that medication will help them to reach their normal life, 13(40.54\%) are adherent where as 22(59.46) are non adherent (as shown in Table 4). There are 40(66.66\%) patients who believe that medications will help to prevent the condition from retaining, 18 (37.5\%) of them are adherent and 25(62.5\%) are non adherent (as shown in Table 4). Thirty five (58.33\%) patients agreed that by long medication, they have identified side effects, $7(20 \%)$ are adherent and $28(80 \%)$ are non adherent (as shown in Table 4), as stated by previous studies Baldessarini RJ et.al. (2008), ${ }^{20}$ Kelly et.al. (2008) ${ }^{21}$ The development of sideeffects is one of the most commonly associated issues with the lack of adherence. 30(50\%) patients agreed that they are worrying about side effects,4(13.33\%) are adherent where as 26(86.67\%) are non adherent (as shown in Table 4). This is in agreement with Marijo B.Tambarrino et.al. (2009) ${ }^{22}$ study in which the same statement was positively answered by (24.8\%) patients who were adherent and (60\%) are non adherent.

Among 35(58.33\%) who said yes for attending regular follow ups17(48.57\%) are adherent where as $18(51.4 \%$ ) are non adherent (as shown in Table 4). 7(11.66\%) patients whom have agreed that their family members or friends are opposing them to take medicines, 2(28.57\%) are adherent and 5(71.42\%) are non adherent (as shown in Table 4). 41(68.33\%) have said that they have financial problem in attending follow-ups, among them $11(26.82 \%)$ are adherent where as 30(73.18\%) are non adherent (as shown in Table 4). Among 57(95\%) of who believed that they need medication correctly, 19(33.33\%) were adherent where as 38(66.66\%) were non adherent (as shown in Table 4).

\section{CONCLUSION:}

The overall Non adherence rate is high in the study. The observed data suggested that age, gender, level of education, marital status, person being breadwinner, occupation, economic status, number of previous admissions, how long the person have been suffering with the disorder and side effects were effecting non adherence. Other modifiable factors such as family support, patient-physician relationship, attitude and beliefs of patient regarding medication affect the adherence to a serious extent. This study concludes that acquainting patient education/counseling and creating the knowledge for the patients to understand the significance of medication adherence can significantly change the scenario. Further research is also recommended in order to investigate other factors that may influence treatment satisfaction. 


\section{ACKNOWLEDGEMENT:}

The author would wish to thank all participants in the study, Dr. N. Uma Jyothi madam, Sk. Shafiya Begum madam.

\section{CONFLICTS OF INTERESTS:}

No conflicts of interest.

\section{REFERENCES:}

1. Alize J. Ferrari, Fiona J. Charlson, Rosana E. Norman, Scott B. Patten, Greg Freedman, Christopher J.L. Murray, Theo Vos, Harvey A. Whiteford, Burden of Depressive Disorders by Country, Sex, Age, and Year: Findings from the Global Burden of Disease Study 2010.

2. Cantopher T (2008) The Depression Self-Help Plan: Depression Advice Line Session (1). Clinical Depression 10.

3. Practice guideline for the treatment of patients with major depressive disorder (revision). American Psychiatric Association. Am J Psychiatry. 2000;157(4 suppl):1-45.

4. Lopez A, Mathers C, Ezzati M, Jamison D, Murray C. Global burden of disease and risk factors. Washington, DC, Oxford University Press and World Bank. 2006.

5. Papakostas GI. Dopaminergic-based pharmacotherapies for depression. Eur Neuro psycho pharmacol. 2006;16:391-402.

6. Andrade L, Caraveo-Anduaga JJ, Berglund P, Bijl RV, De Graaf R, Vollebergh W, et al. The epidemiology of major depressive episodes: results from the International Consortium of Psychiatric Epidemiology (ICPE) Surveys. International journal of methods in psychiatric research. 2003;12(1):3-21.

7. International Statistical Classification of Diseases and Related Health Problems 10th Revision (ICD-10)-2013-WHO Version for;2013.

8. Madhukar H. T, Ella J. D. Treatment strategies to improve and sustain remission in major depressive disorder. Dialogues in Clinical Neuroscience. 2008;10(4):377-384.

9. Moret C. Combination/augmentation strategies for improving the treatment of depression. Neuropsychiatric Disease and Treatment. 2005;1(4):301-309.

10. Delamater AM. Improving patient adherence. Clin Diabetes. 2006; 24: 71-77.

11. Sohini Banerjee and Ravi Prasad Varma, Factors Affecting Non-Adherence among Patients Diagnosed with Unipolar Depression in a Psychiatric Department of a Tertiary Hospital in Kolkata, India. Depression Research and Treatment, vol. 2013, Article ID 809542, 12 pages, 2013. doi:10.1155/2013/809542

12. Ignacio Martinez Parraga, Jesus Lopez-Torres Hidalgo b, Joseph M. del Campo del Campo c, Villena Alejandro Ferrer d, Susana Morena Rayo and, Francisco Escobar Rabadán, Monitoring adherence to antidepressant treatment in patients starting consumption Adherence to antidepressant treatment and the patients Associated factors of non-compiance. J.apirim. 2013;11:26. 
13. M. Sriharsha et al. Treatment And Disease Related Factors Affecting Non-Adherence Among Patients on Long Term Therapy of Antiderpressants. Indo American Journal of Pharm Research.2015;5(03):1016-22.

14. Fenton SW, McGlashan TH, Victor BJ, et al. Symptoms, subtypes and suicidality in patients with schizophrenia spectrum disorder. AM J Psychiatry 1997;154:199-204

15. Jahng KH, Martin LR, Golin CE, et al. Preferences for medical collaboration: patientphysician congruence and patient outcomes.Patient Educ Couns. 2005;57:308-14.

16. Bultman DC, Svarstad BL. Effects of physician communication style on client medication beliefs and adherence with antidepressant treatment. Patient Educ Couns. 2000;40: 173-185.

17. Solberg LI, Fischer LR, Rush WA, et al. When depression is the diagnosis: what happens to patients and are they satisfied? Am J Manag Care. 2003;9(2):131-140.

18. Sirey JA, Bruce ML, Alexopoulos GS, et al. Stigma as a barrier to recovery: perceived stigma and patient-rated severity of illness as predictors of antidepressant drug adherence. Psychiatr Serv 2001;52:1615-20.

19. Kadam UT, Croft P, McLeod J, et al. A qualitative study of patients' views on anxiety and depression. Br J Gen Pract, 2001;51:375-80.

20. Baldessarini RJ, Perry R, Pike J. Factors associated with treatment nonadherence among US bipolar disorder patients. Human Psychopharmacol 2008;23(2):95-105

21. Kelly K, Posternak M, Alpert JE. Toward achieving optimal response: understanding and managing antidepressant side effects.Dialogues Clin Neurosci. 2008;10(4):409-418.

22. Marijo B. Tamburrino, Rollin W. Nagel, Mangeet K. Chahal, Denis J. Lynch, Antidepressant Medication Adherence: A Study of Primary Care Patients Prim Care Companion J Clin Psychiatry 2009;11(5):205-211. 